\title{
Age and risk of major complications in patients undergoing radical cystectomy for muscle invasive bladder cancer
}

\author{
Przemyslaw Adamczyk ${ }^{1}$, Mateusz Kadłubowski ${ }^{1}$, Pawel Pobłocki ${ }^{1}$, Jan Adamowicz ${ }^{2}$, Adam Ostrowski ${ }^{2}$, \\ Tomasz Drewa², Kajetan Juszczak ${ }^{2}$ \\ ${ }^{1}$ Department of General and Oncologic Urology, Nicolaus Copernicus Hospital, Torun, Poland \\ ${ }^{2}$ Clinic of General and Oncological Urology, Collegium Medicum in Bydgoszcz, Nicolaus Copernicus University in Torun, Poland
}

Videosurgery Miniinv 2021; 16 (4): 722-727

DOI: https://doi.org/10.5114/wiitm.2021.103918

\begin{abstract}
Introduction: Radical cystectomy is the treatment of choice for patients with muscle invasive bladder cancer (MIBC), but it may be unsafe in older patients.

Aim: In this study, we investigated whether age and selected clinical characteristics were associated with outcomes of radical cystectomy.

Material and methods: We enrolled 434 patients with MIBC who underwent radical cystectomy between 2012 and 2016, and we classified them into three age groups: $<65,66-74$, and $\geq 75$ years. Postoperative complications were classified on the Clavien-Dindo scale. Regression models were used to find predictors of major postoperative complications (Clavien-Dindo score of 3 or more), long hospital stay (> 7 days), blood loss, and operating time. The models included American Society of Anesthesiologists scores, age group, sex, body mass index, Tumor Nodes Metastasis scores, type of urine derivation (ileal conduit or orthotopic bladder vs. ureterocutaneostomy), and operation type (open vs. laparoscopic).

Results: In the regression models, age was not a significant predictor of major complications, long hospital stay, or blood loss $(p \geq 0.206)$. Older age was associated with shorter surgery times $(p=0.002)$. Higher preoperative American Society of Anesthesiologists scores tended to be associated with a greater risk of major complications (odds ratio, $1.47 ; p=0.092$ ).

Conclusions: Older age was not associated with an increased risk of major complications in patients who undergo radical cystectomy because of MIBC. Therefore, older age alone should not be a contraindication to this operation.
\end{abstract}

Key words: elderly, Clavien-Dindo scale, laparoscopy, urinary bladder neoplasms, ureterocutaneostomy.

\section{Introduction}

Most patients with bladder cancer are 65 years old or older, and bladder cancer is the fourth cause of cancer-related deaths among people 80 or older [1]. Radical cystectomy with pelvic lymphadenectomy is the treatment of choice for patients with muscle invasive bladder cancer (MIBC), because it provides the longest cancer-specific survival [2, 3]. However, the risk of major complications of radical cystectomy may be increased in older patients due to frequent comorbidities among these patients [4-7]. Thus, it is often difficult to qualify elderly patients with MIBC for radical cystectomy and various transurethral procedures are proposed [8]. On the other hand, considerable improvements in perioperative management and a wider availability of minimally invasive procedures, which are associated with low blood loss and short recovery, 
offer a favorable risk-benefit profile for elderly adults who were previously disqualified from surgery [9].

To date, few studies have investigated whether the safety of radical cystectomy in patients with MIBC depends on age. Thus, we compared perioperative complications of radical cystectomy among patients in different age groups in our center.

\section{Aim}

In this study, we investigated whether age and selected clinical characteristics were associated with outcomes of radical cystectomy, performed for invasive urothelial carcinoma.

\section{Material and methods}

\section{Patients}

This work is a retrospective chart review. We enrolled all consecutive patients who underwent radical cystectomy between 2012 and 2016.

Indications for the cystectomy, in accordance with the guidelines of the European Association of Urology (EAU), were as follows: urothelial cT2-cT4a disease or noninvasive papillary cancer that could not be controlled by transurethral resection, as well as other non-urothelial neoplastic disease of the lower urinary tract (due to radiotherapy of prostate cancer or bladder neurogenic dysfunction). During the radical cystectomy, which included resection of the prostate in men and of the reproductive system in woman, we performed bilateral pelvic and iliac lymphadenectomy [10].

\section{Ethical considerations}

The study was a retrospective chart review; thus, informed consent was not required. All procedures performed in studies involving human participants were in accordance with the ethical standards of the local ethic committee and with the Declaration of Helsinki (1964) and its later amendments or comparable ethical standards.

\section{Variables}

Patients were classified into three age groups: $<65$ years, 66-74 years, and $\geq 75$ years. Patients' characteristics included sex, body mass index (BMI), cancer stage - TNM scores, and American Society of Anesthesiologists (ASA) scores [11].
Additionally, we analyzed operating time (duration of anesthesia), length of hospital stays after surgery, and estimated blood loss. Complications were scored on the Clavien-Dindo classification of surgical complications (from grade 1 - any deviation from normal postoperative course, to grade 5 - death) [12]. Major complications were defined as a Clavien-Dindo score of 3 or more.

\section{Statistical analysis}

Clinical characteristics were presented with descriptive statistics. Multivariate logistic regression was used to find predictors of major postoperative complications and long hospital stay ( $>7$ days). Multivariate linear regression was used to find predictors of intraoperative blood loss and operating time. The predictors included ASA score, age group, BMI, TNM score (all as continuous variables), sex, urine derivation (ileal conduit and orthotopic neobladder vs. ureterocutaneostomy), and operation type (laparoscopic vs. open). A $p$-value $<0.05$ was considered statistically significant. The R software (version 3.5.3) was used for all analyses.

\section{Results}

Of all 434 patients enrolled, 146 (34\%) were $\leq 65$ years, 157 (36\%) were 66-74 years, and 131 (30\%) were $\geq 5$ years. About $80 \%$ of all patients in each group were men. In each age group, laparoscopic surgery was performed in about $70 \%$ of patients. Patients aged 75 years and older had ureterocutaneostomy more often and had higher ASA scores than the remaining patients. The clinical characteristics of all patients according to their age group are presented in Table I.

In each age group, about $80 \%$ of complications were minor (grades 1-2), but patients aged $\geq 75$ years had slightly higher (but not significantly) rates of grade- 4 and grade- 5 complications. Hospital stay and blood loss were similar in each age group, whereas operating time was the shortest in patients aged $\geq 75$ years.

In the regression models, age group was not a significant predictor of major complications, long hospital stays, and blood loss ( $p \geq 0.206$, Tables I and II), but older age was associated with shorter surgery times ( $p=0.002$, Table III).

Higher ASA scores tended to be associated with a greater risk of major complications (odds ratio $=$ 
$1.47 ; p=0.092)$; none of the remaining predictors approached statistical significance (Table II).

Compared to ureterocutaneostomy, ileal conduit and orthotopic neobladder were associated with both longer hospital stays and surgery times ( $p \leq$ 0.012, Tables II and III).

Open surgery was associated with longer hospital stays and greater blood loss compared to laparoscopic surgery $(p<0.001$, Tables II and III).
In addition, male sex and lower BMIs were associated with shorter surgery times ( $p \leq 0.010$; Table II).

In order to eliminate the impact of urinary diversion on the results, the whole study group was divided according to the type of diversion. In the subgroup of patients with the simplest derivation (ureterocutaneostomy) in three age groups the number of severe complications is not statistically different between groups.

Table I. Clinical characteristics of patients after radical cystectomy according to age group

\begin{tabular}{|c|c|c|c|}
\hline Parameter & $\begin{array}{l}\text { Patients } \leq 65 \text { years } \\
\quad(n=146)\end{array}$ & $\begin{array}{l}\text { Patients } 66-74 \text { years } \\
\qquad(n=157)\end{array}$ & $\begin{array}{c}\text { Patients } \geq 75 \text { years } \\
(n=131)\end{array}$ \\
\hline Age, median [IQR], N.A. & $59.00[54.25,62.00]$ & $67.00[65.00,70.00]$ & $78.00[75.00,81.00]$ \\
\hline Men, $n(\%)$ & $117(80.1)$ & $125(79.6)$ & $108(82.4)$ \\
\hline BMI, median [IQR], (N.S.) & $25.62[23.11,29.40]$ & $26.79[24.00,30.00]$ & $25.34[22.90,27.80]$ \\
\hline \multicolumn{4}{|l|}{ TNM, $n$ (\%): } \\
\hline O (N.S.) & $29(21.6)$ & $20(13.7)$ & $8(6.9)$ \\
\hline 1 (N.S.) & $22(16.4)$ & $23(15.8)$ & $16(13.8)$ \\
\hline 2 (N.S.) & $27(20.1)$ & $20(13.7)$ & $25(21.6)$ \\
\hline 3 (N.S.) & $19(14.2)$ & $46(31.5)$ & $28(24.1)$ \\
\hline 4 (N.S.) & $37(27.6)$ & $37(25.3)$ & $39(33.6)$ \\
\hline \multicolumn{4}{|l|}{ ASA score, $n(\%)$ : } \\
\hline 1 (N.S.) & $9(6.5)$ & $3(2.1)$ & $0(0.0)$ \\
\hline $2(p=0.032)$ & $59(42.8)$ & $46(31.5)$ & $25(20.7)$ \\
\hline 3 (N.S.) & $61(44.2)$ & $85(58.2)$ & $78(64.5)$ \\
\hline $4(p=0.043)$ & $9(6.5)$ & $12(8.2)$ & $18(14.9)$ \\
\hline \multicolumn{4}{|l|}{ Operation, $n(\%)$ : } \\
\hline Laparoscopic & $107(73.3)$ & $110(70.1)$ & $89(67.9)$ \\
\hline Open & $39(26.7)$ & 47 (29.9) & $42(32.1)$ \\
\hline \multicolumn{4}{|l|}{ Urine derivation, $n(\%)$ : } \\
\hline Ileal conduit ( $p=0.081)$ & $76(52.8)$ & $74(47.1)$ & $33(25.8)$ \\
\hline Orthotopic neobladder & $11(7.6)$ & $17(10.8)$ & $8(6.2)$ \\
\hline Ureterocutaneostomy $(p=0.003)$ & $57(39.6)$ & $66(42.0)$ & $87(68.0)$ \\
\hline \multicolumn{4}{|l|}{ Clavien-Dindo score, $n$ (\%): } \\
\hline 1 (N.S.) & $60(41.4)$ & $68(44.2)$ & $38(29.5)$ \\
\hline 2 (N.S.) & $60(41.4)$ & $61(39.6)$ & $62(48.1)$ \\
\hline 3 (N.S.) & 19 (13.1) & $19(12.3)$ & $11(8.5)$ \\
\hline 4 (N.S.) & $2(1.4)$ & $3(1.9)$ & $10(7.8)$ \\
\hline 5 (death) (N.S.) & $4(2.8)$ & $3(1.9)$ & $8(6.2)$ \\
\hline Operating time, median [IQR] (N.S.) & $270[220,325]$ & $255[200,312]$ & $210[170,270]$ \\
\hline Blood loss, median [IQR] (N.S.) & $350[200,600]$ & $400[200,600]$ & $400[200,700]$ \\
\hline Hospital stay, median [IQR] (N.S.) & $9.00[7.00,12.00]$ & $9.00[7.00,12.00]$ & $8.00[6.00,13.00]$ \\
\hline
\end{tabular}

N.A. - not applicable, N.S. - no significant differences. 
Table II. Logistic regression models predicting major postoperative complications and long hospital stay in patients after radical cystectomy

\begin{tabular}{|lcccc|}
\hline Parameter & \multicolumn{2}{c}{ Major postoperative complications } & \multicolumn{2}{c|}{ Long hospital stay } \\
\cline { 2 - 5 } & Odds ratio $(95 \% \mathrm{Cl})$ & $P$-value & Odds ratio $(95 \% \mathrm{Cl})$ & $P$-value \\
\hline Age group & $1.10(0.76-1.59)$ & 0.593 & $1.24(0.88-1.74)$ & 0.206 \\
\hline Male sex & $1.91(0.89-4.58)$ & 0.113 & $1.01(0.53-1.92)$ & 0.968 \\
\hline ASA score & $1.47(0.93-2.32)$ & 0.092 & $1.33(0.85-2.08)$ & 0.202 \\
\hline BMI & $1.01(0.95-1.07)$ & 0.744 & $0.79(0.92-1.03)$ & 0.434 \\
\hline TNM & $0.96(0.79-1.18)$ & 0.745 & $1.11(0.92-1.34)$ & 0.250 \\
\hline Urine derivation (vs. ureterocutaneostomy): & & & & \\
\hline Ileal conduit & $1.30(0.68-2.46)$ & 0.417 & $6.13(3.40-11.39)$ & $<0.001$ \\
\hline Orthotopic neobladder & $0.3590 .05-1.48)$ & 0.205 & $7.95(1.81-55.85)$ & 0.012 \\
\hline Open operation (vs. laparoscopic) & $1.34(0.662 .64)$ & 0.402 & $9.71(4.09-27.31)$ & $<0.001$ \\
\hline
\end{tabular}

Table III. Linear regression models predicting blood loss and operating time in patients after radical cystectomy

\begin{tabular}{|lcccc|}
\hline Parameter & \multicolumn{2}{c|}{ Blood loss [ml] } & \multicolumn{2}{c|}{ Operating time [min] } \\
\cline { 2 - 5 } & Estimate (standard error) & $P$-value & Estimate (standard error) & $P$-value \\
\hline Age group & $14.17(24.34)$ & 0.561 & $-13.90(4.37)$ & 0.002 \\
\hline Male sex & $-0.43(47.84)$ & 0.993 & $-21.38(8.29)$ & 0.010 \\
\hline ASA score & $20.90(29.94)$ & 0.486 & $-1.66(5.41)$ & 0.758 \\
\hline BMI & $3.17(3.86)$ & 0.413 & $2.58(0.70)$ & $<0.001$ \\
\hline TNM & $7.88(13.39)$ & 0.556 & $0.92(2.43)$ & 0.702 \\
\hline Urine derivation (vs. ureterocutaneostomy): & & & & $<0.001$ \\
\hline Ileal conduit & $-61.48(43.20)$ & 0.156 & $85.10(7.69)$ & $<0.001$ \\
\hline Orthotopic neobladder & $-96.03(74.90)$ & 0.201 & $136.259(14.30)$ & 0.781 \\
\hline Open operation (vs. laparoscopic) & $625.38(49.18)$ & $<0.001$ & $2.35(8.48)$ & $<$ \\
\hline
\end{tabular}

\section{Discussion}

Open radical cystectomy with neoadjuvant or adjuvant chemotherapy is the treatment of choice for both men and women with advanced MIBC. According to the EAU guidelines, this treatment should be offered to most patients, because it is associated with better cure rates than radiotherapy or chemotherapy alone [2-5]. Older age used to be a barrier to surgical treatment in patients with MIBC. It was believed that older patients should not be offered cystectomy due to high rates of complications and death. However, some recent research showed that open radical cystectomy can be safe in elderly patients, with similar mortality and morbidity rates as in younger patients $[13,14]$. In line with previous research, we found that the risk of major complica- tions was similar in all age groups. Reduced complication rates in older patients in more recent studies might be explained by greater availability of minimally invasive operations and better perioperative management $[15,16]$.

In our study, we decided to analyze the predictors of major complications, because most minor complications can be managed successfully and do not increase the risk of postoperative outcomes. We defined major complications as grade 3 or higher on the Clavien-Dindo scale. A similar definition was adopted in many previous studies investigating the outcomes of radical cystectomy [17-21]. About $20 \%$ of all complications were major (Clavien-Dindo Grade 3 or higher) among our patients, which is in line with published data [18]. In previous analyses, 
postoperative death rates after cystectomy varied from $0.3 \%$ to $7.9 \%$, and we observed similar figures in our series [22, 23]. The death rate was the greatest in patients aged $\geq 75$ years; however, the overall death rate was low, so our sample was too small to look for predictors of death in multivariable analyses.

In our study, older age did not increase the risk of major postoperative complications, prolonged hospital stays, or blood loss among patients with MIBC who underwent radical cystectomy. Our findings are in line with previous reports. For example, Lee et al. found no association of age with complication risk among 126 patients after robot-assisted radical cystectomy [24]. Similarly, other studies did not find a significant relationship between age and the risk of complications of radical cystectomy [21, 23, 25]. Among all the studied clinical factors, we found that only higher ASA scores tended to be associated with a greater risk of major complications (similarly to previous reports) $[21,25]$.

When operating on older patients, we consider the following three issues especially important: low blood loss, short operating time, and safe urine derivation. Our findings seem to reflect our approach, because blood loss was similar across all age groups, operating time was shorter in older patients, and ureterocutaneostomy was used most frequently in the oldest patients. The most serious complications in older patients who undergo radical cystectomy are related to the type of urinary diversion [10]. Any type of urine derivation can be offered to older patients who undergo radical cystectomy, but the choice should be made based on the patients' general condition. Because single-site ureterocutaneostomy is simple and associated with few complications, it should be considered in older patients and patients in a poor general condition $[7,15,26]$. Notably, in patients older than 85-90 years, reoperation due to urine leakage frequently leads to death [27]. Although both ileal conduits and orthotopic neobladders were successfully created in our patients, we typically choose simple urine diversions in elderly patients in a poor general condition [5]. In addition, to eliminate the impact of urinary diversion type on the results, the whole study group was divided according to the type of diversion. In the subgroup of patients with the simplest derivation (ureterocutaneostomy) in three age groups the number of severe complications was not statistically significantly different between groups. Therefore it can be assumed that age does not impact per se number of complications on such a great level as it was previously believed [4, 5].

Longer operations are associated with a greater risk; therefore operations in patients who are in a poor general condition should not be prolonged unnecessarily. In our series, the surgery time was the shortest in patients 75 years old and older, which was likely because we often used ureterocutaneostomy in these patients. In regression models, both ileal conduit and orthotopic neobladder substantially prolonged the operating time and increased the risk of a long hospital stay. This is an important finding, because longer operating time is an independent predictor of major postoperative complications after radical cystectomy [21].

Precise surgical technique and coagulation to avoid excessive bleeding can be achieved by both an open approach and with laparoscopy, but the least invasive techniques seem preferable. Thus, we used laparoscopy in about 70\% of all operations. Regression models showed that laparoscopy did not prolong surgery and was associated with lower blood loss and shorter hospital stays.

Our study had limitations. It was retrospective, which could lead to biased assessments of perioperative outcomes. Moreover, the retrospective nature of the study did not allow us to obtain data that could be relevant predictors of postoperative complications, such as smoking status [17]. Although our sample was one of the largest published series among patients after radical cystectomy, it was too small to study the predictors of perioperative death. However, we were able to perform multivariable analyses to investigate other outcomes. It is also important to note that the percentage of elderly patients included in the study group does not represent real life elderly patients with MIBC in our region due to the specific character of our department, which is specialized in surgical treatment of elderly patients, who are disqualified in other places.

\section{Conclusions}

Radical cystectomy can be offered to all patients with MIBC, irrespectively of age. Low blood loss, short surgery times, and urine derivation are important for postoperative outcomes.

\section{Conflict of interest}

The authors declare no conflict of interest. 


\section{References}

1. Edwards BK, Brown ML, Wingo PA, et al. Annual report to the nation on the status of cancer, 1975-2002, featuring population-based trends in cancer treatment. J Natl Cancer Inst 2005; 97: 1407-27.

2. Babjuk M, Burger M, Zigeuner R, et al.; European Association of Urology. EAU guidelines on non-muscle-invasive urothelial carcinoma of the bladder: update 2013. Eur Urol 2013; 64: 639-53.

3. Cookson MS, Chang SS, Wells N, et al. Complications of radical cystectomy for nonmuscle invasive disease: comparison with muscle invasive disease. J Urol 2003; 169: 101-4.

4. Boström PJ, Kössi J, Laato M, Nurmi M. Risk factors for mortality and morbidity related to radical cystectomy. BJU Int 2009; 103: 191-6.

5. Froehner M, Brausi MA, Herr HW, et al. Complications following radical cystectomy for bladder cancer in the elderly. Eur Urol 2009; 56: 443-54.

6. Miller DC, Taub DA, Dunn RL, et al. The impact of co-morbid disease on cancer control and survival following radical cystectomy. J Urol 2003; 169: 105-9.

7. Figueroa AJ, Stein JP, Dickinson M, et al. Radical cystectomy for elderly patients with bladder carcinoma: an updated experience with 404 patients. Cancer 1998; 83: 141-7.

8. Poletajew S, Krajewski W, Stelmach P, et al. En-bloc resection of urinary bladder tumour - a prospective controlled multicentre observational study. Videosurgery Miniinv 2020. doi:10.5114/ wiitm.2020.95399.

9. Deliveliotis C, Papatsoris A, Chrisofos M, et al. Urinary diversion in high-risk elderly patients: modified cutaneous ureterostomy or ileal conduit? Urology 2005; 66: 299-304.

10. McDougal WS, Wein AJ, Kavoussi LR, et al. Campbell-Walsh Urology. 10 $0^{\text {th }}$ ed. Saunders; 2011. https://www.elsevier.com/ books/campbell-walsh-urology-10th-edition-review/mcdougal/978-1-4377-2393-9 accessed 20 July 2020.

11. Sobin LH, Wittekind C. TNM Classification of Malignant Tumours. $6^{\text {th }}$ ed. UICC, $6^{\text {th }}$ ed. New York, Wiley; 2002. https:// www.uicc.org/resources/tnm-classification-malignant-tumours-6th-edition accessed 20 July 2020.

12. Clavien PA, Barkun J, de Oliveira ML, et al. The Clavien-Dindo classification of surgical complications: five-year experience. Ann Surg 2009; 250: 187-96.

13. Jung W, Kim D, Hong S. Long-term results of radical cystectomy in elderly patients with comorbidity. Korean J Urol 2009; 50: 1048-53.

14. Novara G, Catto JW, Wilson T, et al. Systematic review and cumulative analysis of perioperative outcomes and complications after robot-assisted radical cystectomy. Eur Urol 2015; 67: 376-401.

15. Longo N, Imbimbo C, Fusco F, et al. Complications and quality of life in elderly patients with several comorbidities undergoing cutaneous ureterostomy with single stoma or ileal conduit after radical cystectomy. BJU Int 2016; 118: 521-6.

16. Novotny V, Hakenberg OW, Wiessner D, et al. Perioperative complications of radical cystectomy in a contemporary series. Eur Urol 2007; 51: 397-402.
17. Sathianathen NJ, Weight CJ, Jarosek SL, Konety BR. Increased surgical complications in smokers undergoing radical cystectomy. Bladder Cancer 2018; 4: 403-9.

18. Woldu SL, Sanli O, Clinton TN, Lotan Y. Validating the predictors of outcomes after radical cystectomy for bladder cancer. Cancer 2019; 125: 223-31.

19. Ebbing J, Heckmann RC, Collins JW, et al. Oncological outcomes, quality of life outcomes and complications of partial cystectomy for selected cases of muscle-invasive bladder cancer. Sci Rep 2018; 8: 8360.

20. Schulz GB, Grimm T, Buchner A, et al. Surgical high-risk patients with $A S A \geq 3$ undergoing radical cystectomy: morbidity, mortality, and predictors for major complications in a high-volume tertiary center. Clin Genitourin Cancer 2018; 16: e1141-9.

21. Ng CK, Kauffman EC, Lee MM, et al. A comparison of postoperative complications in open versus robotic cystectomy. Eur Urol 2010; 57: 274-82.

22. Aziz A, May M, Burger M, et al.; PROMETRICS 2011 research group. Prediction of 90-day mortality after radical cystectomy for bladder cancer in a prospective european multicenter cohort. Eur Urol 2014; 66: 156-63.

23. Young MJ, Elmussareh M, Weston P, Dooldeniya M. Radical cystectomy in the elderly - is this a safe treatment option? Arab J Urol 2017; 15: 360-5.

24. Lee CU, Kang M, Kim TJ, et al. Predictors of postoperative complications after robot-assisted radical cystectomy with extracorporeal urinary diversion. Cancer Manag Res 2019; 11: 5055-63.

25. Tsaturyan A, Petrosyan V, Crape B, et al. Risk factors of postoperative complications after radical cystectomy with continent or conduit urinary diversion in Armenia. Springerplus 2016; 5: 134.

26. Kilciler M, Bedir S, Erdemir F, et al. Comparison of ileal conduit and transureteroureterostomy with ureterocutaneostomy urinary diversion. Urol Int 2006; 77: 245-50.

27. Chavan S, Bray F, Lortet-Tieulent J, et al. International variations in bladder cancer incidence and mortality. Eur Urol 2014; 66 : 59-73.

Received: 6.12.2020, accepted: 3.01.2021. 